Original article

\title{
Developmental trajectories of gambling severity after cognitive-behavioral therapy
}

\author{
Susana Jiménez-Murcia ${ }^{a, b, c, *, 1}$, Roser Granero ${ }^{\mathrm{b}, \mathrm{d}, 1}$, Fernando Fernández-Aranda ${ }^{\mathrm{a}, \mathrm{b}, \mathrm{c}}$, \\ Neus Aymamía , Mónica Gómez-Peñaa ${ }^{a}$, Gemma Mestre-Bach ${ }^{\mathrm{a}, \mathrm{b}, \mathrm{c}}$, Trevor Steward ${ }^{\mathrm{a}, \mathrm{b}, \mathrm{c}}$, \\ Amparo del Pino-Gutiérrez ${ }^{\mathrm{a}, \mathrm{e}}$, Teresa Mena-Moreno ${ }^{\mathrm{a}, \mathrm{b}}$, Cristina Vintró-Alcaraz ${ }^{\mathrm{a}, \mathrm{b}}$, \\ Zaida Agüera ${ }^{a, b}$, Jéssica Sánchez-González ${ }^{a}$, Laura Moragas ${ }^{a}$, Ester Codina ${ }^{a, e}$, \\ José M. Menchón ${ }^{\mathrm{a}, \mathrm{c}, \mathrm{f}}$
}

a Department of Psychiatry, Bellvitge University Hospital-IDIBELL, Barcelona, Spain

b CIBER de Fisiopatología de la Obesidad y Nutrición (CIBERobn), Instituto de Salud Carlos III, Barcelona, Spain

${ }^{\mathrm{c}}$ Department of Clinical Sciences, School of Medicine and Health Sciences, University of Barcelona, Spain

d Departament de Psicobiologia i Metodologia, Universitat Autònoma de Barcelona, Spain

e Department of Public Health, Mental Health and Mother-Infant Nursing, University School of Nursing, University of Barcelona, Spain

${ }^{f}$ CIBER Salud Mental (CIBERSAM), Instituto de Salud Carlos III, Barcelona, Spain

\section{A R T I C L E I N F O}

\section{Article history:}

Received 5 December 2018

Received in revised form 2 April 2019

Accepted 3 April 2019

Available online 14 May 2019

\section{Keywords:}

Gambling disorder

Developmental trajectories

Treatment

Personality

Psychopathology

Severity

\begin{abstract}
A B S T R A C T
Aims: To estimate trajectories of the gambling disorder (GD) severity for 12 months following a manualized cognitive-behavior-therapy (CBT) program, and to identify the main variables associated with each trajectory.

Methods: Latent Class Growth Analysis examined the longitudinal changes of $n=603$ treatment-seeking patients with GD.

Results: Five separate empirical trajectories were identified: $\mathrm{T} 1(n=383,63.5 \%)$ was characterized by the most highest baseline gambling severity levels and positive progress to recovery during the follow-up period; T2 $(n=154,25.5 \%)$ featured participants with high baseline gambling severity and good progress to recovery; T3 $(n=30,5.0 \%)$ was made up of patients with high gambling baseline severity and slow progress to recovery; T4 $(n=13,2.2 \%)$ and T5 $(n=23,3.8 \%)$ contained participants with high baseline gambling severity and moderate (T4) and poor (T5) progress in GD severity during the follow-up. Psychopathological state and personality traits discriminated between trajectories. Poor compliance with the therapy guidelines and the presence of relapses also differed between the trajectories.

Conclusions: Our findings show that patients seeking treatment for GD are heterogeneous and that trends in progress following treatment can be identified considering sociodemographic features, psychopathological state and personality traits. These results could be useful in developing more efficient interventions for GD patients.
\end{abstract}

(c) 2019 Published by Elsevier Masson SAS.

\section{Introduction}

Gambling disorder (GD) is characterized by repeated compulsive problematic gambling behavior accompanied by unsuccessful and uncontrollable urges to keep gambling, which leads to

\footnotetext{
* Corresponding author at: Department of Psychiatry, Bellvitge University Hospital-IDIBELL and CIBERObn, c/ Feixa Llarga s/n, 08907, Hospitalet de Llobregat, Barcelona, Spain.

E-mail address: sjimenez@bellvitgehospital.cat (S. Jiménez-Murcia).

1 Shared first authorship.
}

considerable distress and impairment [1]. Risk factors for developing GD include male gender, poor school performance and cognitive distortions surrounding gambling [2,3]. Several distinct types of interventions exist to treat GD [4-7], with cognitive behavior therapy (CBT) being one of the most widely used approaches [8].

Multiple studies have assessed which factors are the most related to the effectiveness of CBT in GD patients, particularly when considering clinical state immediately after the end of the intervention and during the first months following the intervention $[9,10]$. Short-term effectiveness appears to be particularly related to psychopathological state at the beginning of the therapy 
(particularly lower depression and anxiety levels), followed by gender, older age, lower baseline gambling severity levels, lower comorbidity, and a more functional personality profile [11-13]. Long-term recovery has not been so widely studied, but it seems to be most associated with lower levels of psychopathology, sensation seeking and GD severity at the start of treatment [14,15].

Despite the evidence supporting the usefulness of CBT in the treatment of GD, some systematic reviews have underscored the paucity of evidence of effective treatment programs, and controversy has emerged in the interpretation of results [16,17]. The very definition of recovery remains unclear and many outcome measures incorporate broader domains extending beyond disorder-specific symptoms. Few long-term studies on gambling relapse have been conducted, the durability of the therapeutic gains is unknown and the evidence about the effects of benefits from integrative therapies has been obtained from few studies with limited sample sizes [18,19]. Moreover, although controlled studies have shown positive results in the treatment of GD, indicating the effectiveness of interventions, many of these studies had multiple limitations $[5,11,20]$. Namely, the lack of a single comprehensive scale to measure all aspects of gambling recovery hinders uniform reporting practices across the field [17] and the heterogeneity of populations markedly differ across studies, leading to discrepant results [4]. There is progress stillyet to be made as approximately $50 \%$ of individuals affected by GD will continue to have symptoms throughout life $[14,15]$.

The capacity of CBT to treat GD has been analyzed through variable-level techniques (such as the correlation models, regression techniques, analysis of variance or path analysis), which are focused on examining the relationships between the potential variables (in this case, predictors and therapy outcomes) by considering the individuals as a group. In this sense, variable-level analyses tend to isolate clinically significant features in which individuals differ, since they are centered on the analysis of the potential correlational structure of the variables, their stability over time, and their predictive capacity for predetermined criteria. Therefore, variable-level approaches do not provide information on person-specific, intra-individual clinical states, nor on personspecific intra-individual dynamics.

An alternative to variable-level approaches are person-centered approaches (such as mixed growth modeling or developmental trajectories). These techniques focus attention on the intraindividual structure of variables with the aim of identifying groups of individuals who share particular attributes or relationships among attributes, with the consequent advantage of conceiving the individuals as a whole and not as the sum of isolated features [21,22]. Although person-centered techniques have been used for exploring group differences in patterns of development, few studies have focused the study of GD based on developmental trajectories analyses [3,23-28]. To our knowledge only one study to date has been focused on GD trajectories after treatment [29]. This person-centered approach would be in the line of precision treatments, adapted to the specific needs of each patient, their risk factors and the phenotypic characteristics of the patient's disorder. This therapeutic perspective, based on the issue "which medication will work best for which patient" [30], is oriented to identify homogeneous subtypes of patients in order to predict response to treatment [31]. Thus, precision medicine is being extended to all areas of health, including mental health and addictions, improving prediction of response to treatment [32]. In this vein, Dowling et al. [3] identified several psychosocial risk factors associated with problem gambling such as sociodemographic variables, substance abuse, antisocial behavior, personality traits, the number of gambling activities and poor school performance. Moreover, other studies reported some variables associated with the poor treatment outcome failure as younger age [18], early age of onset and low school education [13], negative urgency [15], high impulsivity levels [33], low coping skills, high sensation-seeking, low tolerance to boredom and craving [34]. Social support is also known to be associated with a positive response to therapy [35-37]. All these variables may contribute to the development of intervention programs based on precision medicine. As such, the aim of the present study was to estimate developmental trajectories of GD severity course during the 12 months following a manualized CBT program, and to identify the main variables associated with each trajectory.

This work used and integrate both person-centered and variable-level approaches: a) in the first stage, Latent Class Growth Analysis was used as a person-centered procedure, which aimed is to investigate how a single outcome variable (GD severity measured at multiple time points) defined a latent class model in which latent classes correspond to different growth curve shapes for the outcome variable; and b) in the second stage, the exploration of what sociodemographic and clinical variables were related with the previous empirical developmental trajectories based on analysis of variables procedures.

Based on the existing scientific evidence [3], we hypothesized that distinguishable GD trajectories would be latent in our sample, and that poor progress in gambling recovery would be related to poorer pre-treatment psychological state and more maladaptive personality profiles [38]. Cognitive distortions and higher levels of psychopathology have all been linked to greater levels of GD severity, and it is for these reasons we hypothesize that these very factors will distinguish our groups $[2,39]$. The identification of variables associated with the classification obtained in the latent class analysis could potentially allow for the development of more effective intervention programs for treatment-seeking patients.

\section{Material and methods}

\subsection{Participants}

The sample included consecutively admitted patients who met DSM-5 criteria for GD. Patients voluntarily sought outpatient treatment at a specialized Gambling Disorder Unit at Bellvitge University Hospital in Barcelona, Spain, and completed manualized a CBT intervention program between January-2007 and October2017. Since the number of women was very low $(n=14)$ and the high asymmetry in the distribution of the sex could bias results, only men were included in our analyses. Therefore, the final sample included $n=603$ treatment-seeking male patients, aged between 19 and 75 .

Table 1 includes a description of the sample at the beginning of the study (pre-treatment, baseline state).

\subsection{Psychological assessment}

The assessment included specific measures of GD, global psychopathology and personality traits. Table 1 includes the Cronbach's alpha $(\alpha)$ coefficients estimated in the study sample for the questionnaires used.

\subsubsection{Diagnostic questionnaire for pathological gambling according to DSM criteria}

This 19-item questionnaire assesses the DSM-IV [40] diagnostic criteria for pathological gambling. Then, all patient diagnoses were reassessed and recodified post hoc via a computerized system and, in our analysis, only patients who met DSM-5 criteria for GD were included. Convergent validity with the external gambling scores in the original version was very good $(r=.77$ for representative samples and $r=.75$ for gambling treatment groups [41]. Internal consistency in the Spanish adaptation used in this study was $\alpha=.81$ for the general population and $\alpha=.77$ for gambling treatment 
Table 1

Sample description at baseline $(n=603)$.

\begin{tabular}{|c|c|c|c|c|c|c|c|c|c|c|}
\hline Sociodemographic & $n$ & $\%$ & Gambling variables & $\alpha$ & Mean & $S D$ & Psychopathology (SCL-90R) & $\alpha$ & Mean & $S D$ \\
\hline \multicolumn{11}{|l|}{ Civil status } \\
\hline Single & 188 & 31.2 & Age (years-old) & & 44.67 & 13.54 & Somatization & .889 & 0.84 & 0.73 \\
\hline Married-partner & 354 & 58.7 & Age of GD onset (years-old) & & 30.10 & 11.67 & Obsessive/comp. & .885 & 1.02 & 0.74 \\
\hline Separated-divorced & 61 & 10.1 & Duration of GD (years) & & 14.89 & 8.03 & Interpersonal sensitivity & .839 & 0.89 & 0.73 \\
\hline \multicolumn{11}{|l|}{ Education level } \\
\hline Primary & 330 & 54.7 & DSM-5 total criteria & .763 & 6.87 & 1.79 & Depressive & .897 & 1.39 & 0.84 \\
\hline Secondary & 242 & 40.1 & SOGS-total score & .781 & 10.74 & 2.80 & Anxiety & .873 & 0.89 & 0.71 \\
\hline University & 31 & 5.1 & Personality (TCI-R) & & & & Hostility & .814 & 0.81 & 0.72 \\
\hline \multicolumn{11}{|l|}{ Social status } \\
\hline High + mean-high & 37 & 6.1 & Novelty seeking & .757 & 107.80 & 14.32 & Phobic anxiety & .773 & 0.37 & 0.55 \\
\hline Mean & 76 & 12.6 & Harm avoidance & .811 & 100.07 & 16.70 & Paranoid Ideation & .754 & 0.78 & 0.70 \\
\hline Mean-low & 216 & 35.8 & Reward dependence & .772 & 98.94 & 14.81 & Psychotic & .832 & 0.83 & 0.69 \\
\hline Low & 274 & 45.4 & Persistence & .864 & 108.53 & 19.73 & GSI score & .975 & 0.95 & 0.62 \\
\hline \multicolumn{11}{|l|}{ Employment } \\
\hline Unemployed & 229 & 38.0 & Self-directedness & .837 & 128.86 & 20.25 & PST score & .975 & 43.98 & 20.22 \\
\hline Employed & 374 & 62.0 & Cooperativeness & .789 & 132.49 & 15.59 & PSDI score & .975 & 1.82 & 0.54 \\
\hline \multicolumn{11}{|l|}{ Origin } \\
\hline Spain & 586 & 97.2 & Self-Transcendence & .822 & 63.46 & 14.79 & & & & \\
\hline Immigrant & 17 & 2.8 & & & & & & & & \\
\hline
\end{tabular}

Note. SD: standard deviation. $\alpha$ : Cronbach's alpha in the study sample.

samples [42]. In this study, the total number of DSM-5 criteria for GD was analyzed ( $\alpha=.76$ in the sample).

\subsubsection{South oaks gambling screen (SOGS)}

This questionnaire is commonly used to evaluate gambling severity in research and clinical settings. It includes 20 items to assess cognitions and behaviors related to problem gambling. The validated Spanish version of the SOGS has shown high internal consistency (Cronbach's alpha $\alpha=.94$ ) and good test-retest reliability $(r=0.98)$ [43]. The internal consistency in the study sample was adequate $(\alpha=.78)$.

\subsubsection{Symptom checklist-90 items-revised (SCL-90-R)}

This is a 90-item self-report tool used to assess global psychopathology through nine primary symptom dimensions (obsessive-compulsive, depression, anxiety, hostility, interpersonal sensitivity, phobic anxiety, somatization, paranoid ideation and psychoticism) and three derived global indices [global severity index (GSI), positive symptom total (PST), and positive symptom distress index (PSDI)]. Good psychometrical properties were found in Spanish samples [44]. Internal consistency ranged between $\alpha=.77$ for phobic anxiety to $\alpha=.98$ for the global composite indexes in the study sample.

\subsubsection{Temperament and character inventory-revised (TCI-R)}

This is a 240-item tool used to measure four temperament dimensions (harm avoidance, novelty seeking, reward dependence and persistence) and three character scales (self-directedness, cooperativeness and self-transcendence) of personality. The adaptation of Spanish version of the questionnaire obtained good psychometrical properties [45]. Internal consistency ranged between $\alpha=.76$ for novelty seeking and $\alpha=.86$ for persistence in the study sample.

\subsubsection{Other sociodemographic and clinical variables}

Additional sociodemographic data were taken using a semistructured, face-to-face clinical interview described elsewhere [46], including the following variables:

2.2.5.1. Socio-demographic variables. Sex, current marital status (single, married or with a stable partner, divorced or separated, widowed), social status by means of Hollingshead [27], currently receiving personal income, currently in employment, receipt of social aid, number of co-inhabitants, presence of overcrowded living conditions (i.e., having to share a bedroom with a person who is not one's partner), age (in years), personal income (monthly average, in euros) and family income (monthly average, in euros).

2.2.5.2. Current state of physical and mental health. Current treatment for physical health problems, smoking habit, alcohol consumption, consumption of illegal substances, regular consumption of non-prescription medication, current treatment for psychological problems, past treatment history for psychological problems, presence of close relatives who have or have had psychological problems requiring treatment

2.2.5.3. Gambling profile. Main gambling activity was identified and for each gambling activity, the following were measured: age of initiation, duration, frequency, bets (average and maximum), current treatment for gambling behavior, previous life history for gambling behavior treatment.

2.2.5.4. Gambling behavior. Total past debts accumulated by the subject due to gambling, total current debts accumulated by the subject due to gambling, cognitive distortions attributable to gambling (gambling expectations, illusion of control, predictive control, interpretative bias).

\subsection{Procedure}

All participants were assessed in two face-to-face clinical interviews by expert clinical psychologists with more than 15 years of experience in the field of behavioral addictions, who also guided the administration of questionnaires. In the first clinical interview, the psychologists or psychiatrists who attended the patient proposed participation in the project, providing informed consent, which was signed in the case of acceptance. The decision on participation in the study was autonomous and voluntary. The head of the project (SJM) ensured that the care or services they would receive at the hospital would not be affected regardless of their decision. In addition, if the patient decided to withdraw from the study once participation had begun and/or wanted to 
withdraw their data from the database, they could do so by contacting the head of the project. The therapist leading the CBT group gave the patients a calendar with all the scheduled sessions (including follow-up sessions) at the beginning of the treatment program. The same clinical psychologist (who did the first interview and the assessment) carried out the CBT therapy intervention and weekly case discussions were held between the therapists and the rest of the team at the Unit.

The present study was approved by the Ethics Committee of Bellvitge University Hospital and all patients provided signed informed consent. Psychological measures were obtained by experienced clinical psychologists at the Department of Psychiatry of Bellvitge University Hospital.

Data analyzed in this study correspond to data taken at the start of the CBT program, immediately following CBT, and measures obtained during the 12 months following the end of the program (data was obtained 1, 3, 6 and 12 months after the completion of the CBT program).

The Cognitive-behavioral therapy (CBT) intervention utilized in this study was carried out in a group format (averaging approximately 10 patients-per-group). It consisted of 16 weekly outpatient sessions lasting about $45 \mathrm{~min}$ each. The aim of the intervention was to train patients to implement CBT strategies in order to attain full recovery (defined as the absence of gambling episodes). The general topics addressed in the program included psychoeducation regarding GD (its onset and course, vulnerability factors, diagnostic criteria, bio-psychosocial models, etc.), stimulus control (such as money management and the avoidance of potential triggers), response prevention strategies (alternative and compensatory behaviors), the acquisition of new, healthy behaviors to replace $\mathrm{GD}$, cognitive restructuring focused on illustrating and rectifying false beliefs of control over gambling, reinforcement and self-reinforcement, skills training and relapse prevention techniques. The therapists who conducted the groups are the same clinical psychologists who performed the first interviews and evaluations. These three therapists share the same background in CBT training, extensive experience in motivational interviewing, as well as a deep knowledge of the manualized treatment protocol used at the unit. In relation to adherence to treatment, the variables considered are compliance with guidelines, self-monitoring, etc. and three categories of compliance were established: good, regular and bad, depending on the level of fulfillment of the instructions provided by the therapist.

A full description of this CBT program has been previous published [47] and its short- and long-term effectiveness has been described elsewhere $[15,48,49]$.

\subsection{Statistical analyses}

Statistical analyses were carried out with MPlus8 for Windows. The trajectories were estimated using the SOGStotal scores obtained during the first year after completion of the CBT, which was defined as a measure of gambling problem severity. Due to the strong association between the decreases in severity and the initial (baseline) gambling severity, estimation was carried out including baseline SOGS-total scores as a covariate. Latent Class Growth Analysis (LCGA) was used, defining the robust maximum likelihood (MLR) estimator in the Analysis command (full information on this method is presented in: [50,51] and using Lo-Mendell-Rubin [52] as a measure to determine the number of classes. LCGA constitute a special type of Growth Mixture Modeling, with the peculiar consideration that individuals within a class are homogenous and therefore variance and covariance estimates for the growth factors within each class are set to zero [53,54]. TYPE = MIXTURE in MPlus syntax was defined and the MODEL command set at 0,1 ,
2, 3 and 4 the time scores for the slope growth factor to define a linear growth model with equidistant time points (at posttherapy and at months 3-6-9-12 of the follow-up). In the estimation procedure, solutions with quadratic and cubic components were tested, but they were rejected because these potential solutions did not provide substantively better statistical adjustment and/or models with better clinical interpretation, and therefore simpler solutions with linear components were selected for the sake of parsimony. The selection of the number of trajectories was based on [55]: a) the lowest Akaike (AIC) and Bayesian information criterion (BIC) indexes for the model (compared with other solutions); b) entropy (measure of the model's discriminative capacity, that is, its ability to identify individuals following the different trajectories) above .80 ; c) high on-diagonal average values (around .80 ) in the matrix containing the probabilities of membership (that is, high average latent class probabilities for most likely latent class membership by latent class); d) enough sample size in a class/trajectory to allow for statistical comparisons; and e) adequate clinical interpretability.

The distribution of the characteristics of participants (sociodemographic, personality and psychopathological levels) across the identified trajectories was examined with chi-square tests for categorical variables and analysis of variance (ANOVA) for quantitative variables. The list of features examined included the sociodemographic variables measured at the beginning of the study, gambling related variables at baseline, psychopathology and personality at baseline, psychopathology at the end of the therapy program, adherence to the therapy program and the presence of relapses during the program and during the follow-up episodes (relapses were defined as the presence of gambling episodes). Cohen's- $d$ coefficient measured effect size for pairwise comparisons $(|d|>0.20$ was considered low effect size, $|d|>0.50$ moderate effect size and $|d|>0.80$ good effect size [56]. Increase in Type-I error due to multiple statistical comparisons was controlled with Simes' correction method, a familywise error rate stepwise procedure which offers more powerful test than the classical Bonferroni correction [57].

Finally, a multinomial logistic regression was performed to model the predictive contribution of the measures at the beginning of the study (defined as independent variables) on membership in the 5 groups obtained in the LCGA (defined as the dependent variable). The multinomial regression is a generalization of logistic regression to multiclass problems (i.e. categorical criteria with more than two levels), and therefore it allows for the prediction of the probabilities of the different levels of a categorically distributed dependent variable considering a set of independent variables. In this study, due to the large set of independent variables, three separate models were obtained: a) for the sociodemographic variables (civil status, education level, social position index, employment status and origin of the sample); b) for gambling related variables and global psychopathological state (patients' age, GD duration, DSM-5 total criteria for GD, debts due to gambling and SCL-90R GSI); and c) for personality traits (TCI-R scores). The final models presented in this study retained only those independent variables with a significant contribution on the criterion.

\section{Results}

\subsection{GD course trajectories}

Table 2, contains the goodness-of-fit and the mean estimates for the candidate models obtained in the LCGA, with a number of trajectories ranging from 2 to 5 groups. Solution models for more than 5 trajectories were not considered due to small group size to allow for subsequent statistical comparisons (for example, the 6- 
Table 2

Coodness-of-fit indexes for LCGA candidate solutions.

\begin{tabular}{|c|c|c|c|c|c|c|c|c|c|c|c|c|c|c|c|c|}
\hline \multirow{2}{*}{$\begin{array}{l}\text { Model } \\
\text { d\#trajec. }\end{array}$} & \multirow{2}{*}{$\begin{array}{l}\text { Akaike } \\
\text { AIC }\end{array}$} & \multirow{2}{*}{$\begin{array}{l}\text { Bayesian } \\
\text { BIC }\end{array}$} & \multirow{2}{*}{$\begin{array}{l}{ }^{\text {a Adjusted }} \\
\text { BIC }\end{array}$} & \multirow{2}{*}{$\begin{array}{l}\text { b'LMR- } \\
\text { LRT }\end{array}$} & \multirow{2}{*}{$\begin{array}{l}\text { 'Boost. } \\
\text { BLRT }\end{array}$} & \multirow{2}{*}{$\begin{array}{l}\text { Entro- } \\
\text { phy }\end{array}$} & & \multirow{2}{*}{\multicolumn{2}{|c|}{$\frac{\text { Count-size }}{n-\%}$}} & \multirow{2}{*}{$\begin{array}{l}\text { On-diagonal } \\
\text { posterior prob. }\end{array}$} & \multicolumn{6}{|c|}{ Estimated means (SOGS-total score) } \\
\hline & & & & & & & & & & & Pre & Post & 3-month & 6-month & 9-month & 12-month \\
\hline $1-\operatorname{tr}$ & 13324.5 & 13395.0 & 13344.2 & - & - & 1.00 & $\mathrm{~T} 1$ & 603 & $100 \%$ & 1.00 & 10.74 & 2.76 & 2.71 & 2.63 & 2.55 & 2.47 \\
\hline \multirow[t]{2}{*}{$2-\operatorname{tr}$} & 13031.2 & 13123.6 & 13056.9 & 294.18 & -6646.3 & .860 & T1 & 551 & $91.4 \%$ & .996 & 10.71 & 2.44 & 2.44 & 2.44 & 2.44 & 2.45 \\
\hline & & & & $(.040)$ & $(<.001)$ & & $\mathrm{T} 2$ & 52 & $8.6 \%$ & .824 & 11.05 & 6.25 & 5.60 & 4.64 & 3.67 & 2.70 \\
\hline \multirow{3}{*}{$3-\operatorname{tr}$} & 12853.7 & 12968.2 & 12885.6 & 181.75 & -6494.6 & .812 & $\mathrm{~T} 1$ & 393 & $65.2 \%$ & .924 & 11.55 & 2.47 & 2.48 & 2.49 & 2.50 & 2.52 \\
\hline & & & & $(<.001)$ & $(<.001)$ & & $\mathrm{T} 2$ & 51 & $8.5 \%$ & .927 & 11.01 & 6.27 & 5.62 & 4.65 & 3.69 & 2.72 \\
\hline & & & & & & & T3 & 159 & $26.4 \%$ & .879 & 8.80 & 2.38 & 2.36 & 2.33 & 2.30 & 2.27 \\
\hline \multirow[t]{4}{*}{4 -tr } & 12743.5 & 12880.0 & 12781.6 & 116.54 & -6400.9 & .814 & $\mathrm{~T} 1$ & 24 & $4.0 \%$ & .847 & 11.18 & 3.92 & 4.63 & 5.71 & 6.79 & 7.87 \\
\hline & & & & $(.728)$ & $(<.001)$ & & $\mathrm{T} 2$ & 388 & $64.3 \%$ & .901 & 11.53 & 2.50 & 2.42 & 2.40 & 2.33 & 2.28 \\
\hline & & & & & & & T3 & 37 & $6.1 \%$ & .938 & 11.04 & 6.66 & 5.85 & 4.63 & 3.40 & 2.18 \\
\hline & & & & & & & $\mathrm{T} 4$ & 154 & $25.5 \%$ & .874 & 8.83 & 2.20 & 2.22 & 2.16 & 2.20 & 2.15 \\
\hline \multirow[t]{5}{*}{$5-\operatorname{tr}$} & $12,633.1$ & $12,791.5$ & $12,677.2$ & 161.66 & -6363.9 & .877 & $\mathrm{~T} 1$ & 383 & $63.5 \%$ & .868 & 11.50 & 2.47 & 2.42 & 2.33 & 2.25 & 2.16 \\
\hline & & & & (.183) & $(<.001)$ & & T2 & 154 & $25.5 \%$ & .870 & 8.84 & 2.20 & 2.10 & 2.00 & 2.00 & 2.00 \\
\hline & & & & & & & T3 & 30 & $5.0 \%$ & .917 & 11.32 & 6.85 & 5.91 & 4.50 & 3.09 & 1.69 \\
\hline & & & & & & & $\mathrm{T} 4$ & 13 & $2.2 \%$ & .862 & 11.54 & 2.95 & 3.30 & 3.60 & 3.90 & 4.10 \\
\hline & & & & & & & $\mathrm{T} 5$ & 23 & $3.8 \%$ & .869 & 10.92 & 4.38 & 5.02 & 5.97 & 6.93 & 8.00 \\
\hline \multirow[t]{6}{*}{$6-\operatorname{tr}$} & 12625.5 & 12805.9 & 12675.8 & 38.80 & -6291.7 & .859 & T1 & 15 & $2.5 \%$ & .803 & 11.32 & 5.65 & 6.10 & 6.79 & 7.48 & 8.16 \\
\hline & & & & $(.969)$ & $(<.001)$ & & T2 & 19 & $3.2 \%$ & .931 & 11.19 & 7.06 & 5.96 & 4.33 & 2.69 & 1.05 \\
\hline & & & & & & & T3 & 147 & $24.4 \%$ & .817 & 8.78 & 2.29 & 2.28 & 2.25 & 2.23 & 2.21 \\
\hline & & & & & & & $\mathrm{T} 4$ & 3 & $0.5 \%$ & .999 & 11.68 & 10.65 & 9.03 & 6.60 & 4.17 & 1.74 \\
\hline & & & & & & & T5 & 65 & $10.8 \%$ & .866 & 11.13 & 4.26 & 3.94 & 3.46 & 2.98 & 2.50 \\
\hline & & & & & & & T6 & 354 & $58.7 \%$ & .914 & 11.49 & 2.26 & 2.28 & 2.32 & 2.36 & 2.40 \\
\hline
\end{tabular}

Note

a Sample-size adjusted BIC.

Lo-Mendell-Rubin Adjusted Likelihood Ratio Test: value (significance).

c Boostrapped Likelihood Ratio Test (BLRT): loglikelihood ivalue (significance)

d Number of trajectories. 


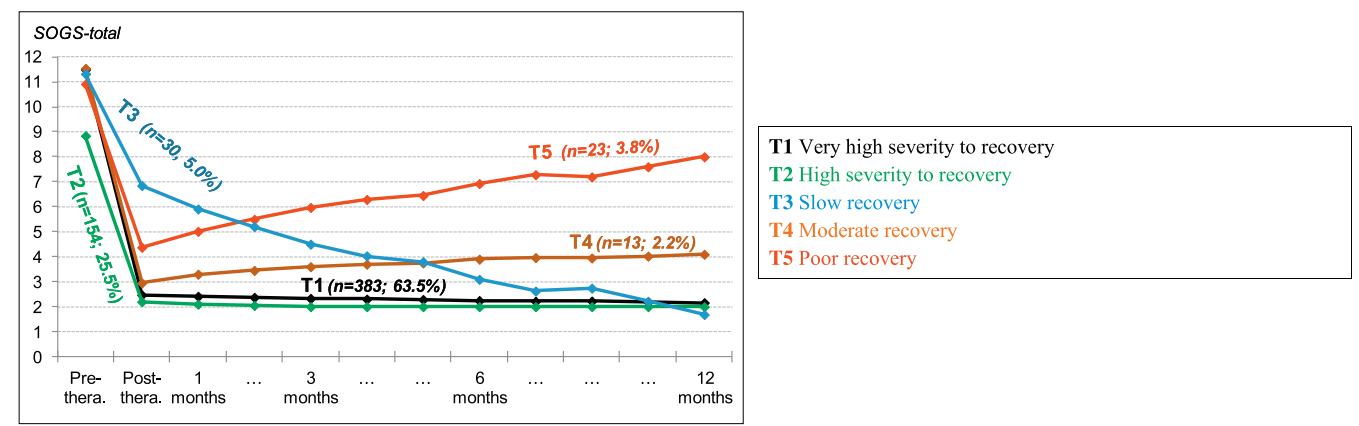

Fig. 1. Course trajectories: from pre-treatment to 12 -months following the CBT program $(n=603)$.

classes model included a group with only 3 participants). The final model selected was the 5-trajectory solution (Fig. 1 includes the shapes for the SOGS evolution from baseline to the year following treatment). This model yielded the lowest AIC-BIC indexes ( $\mathrm{AIC}=12633.1, \quad \mathrm{BIC}=12,791.5$ and adjusted sample-size $\mathrm{BIC}=$ $12,677.2)$, excellent entropy (.877), very high on-diagonal values in the matrix with the average latent class probabilities (between .868 and .917$)$, and good clinical interpretability.

\subsection{Comparison between trajectories at baseline}

Tables 3 and 4 include the comparison between trajectories in terms of sociodemographic and clinical variables taken at the start of the CBT program (at the beginning of the study).

Trajectory T1 $(n=383,63.5 \%)$ represented patients with very high GD severity at baseline (mean SOGS $=11.5$ ) and good progress to recovery (mean SOGS $=2.5$ at post-treatment and 2.2 at the end of the follow-up period). This group was characterized by the high scores in psychopathology (as determined by the SCL-90-R) and high scores in novelty seeking at baseline.

Trajectory T2 $(n=154,25.5 \%)$ represented patients with high GD severity at baseline (mean SOGS $=8.8$ ) and good progress to recovery (mean SOGS $=2.2$ at the end of the treatment and 2.0 at the end of the follow-up period). This class is characterized by the lowest scores in psychopathology state at baseline, low scores in novelty seeking and harm avoidance and high scores in reward dependence, persistence, self-directedness and cooperativeness. Trajectory T2 also included the highest proportion of patients that were married or living with a stable partner, but the lowest proportion of patients with debts due to gambling behavior.

Trajectory T3 $(n=30,5.0 \%)$ represented patients with high levels of GD severity at baseline (mean SOGS $=11.3$ ) and slow progress to recovery (mean SOGS $=6.85$ at post-therapy and 1.7 at the end of the follow-up period). This trajectory included patients with moderate levels of psychopathology and high scores in novelty seeking and reward dependence at baseline.

Trajectory T4 $(n=13,2.2 \%)$ represented patients with very high GD severity at baseline (mean SOGS $=11.5$ ) and moderate progress in obtaining recovery (mean SOGS $=3.0$ at post-CBT and 4.1 at the 12-month follow-up). This trajectory grouped patients with worse psychopathological state at baseline, high scores in harm avoidance and low scores in persistence. Trajectory T4 also included the highest proportion patients that were single, as well as the highest percentage of patients with debts due to gambling behavior.

Trajectory T5 ( $n=13,2.2 \%)$ represented patients with very high GD severity at baseline (mean SOGS $=10.9$ ) and poor progress at the end of the follow-up period (mean SOGS $=4.4$ at posttreatment and 8.0 at the 12 -month follow-up). This class agglomerated patients with moderate psychopathological impairment and low scores in reward dependence and persistence.

Fig. 2 contains a radar-chart to graphically illustrate the main differences between trajectories for the psychological variables registered at baseline ( $\mathrm{z}$-standardized means have been plotted to allow for easier interpretation due to the different scale ranges).

\subsection{Comparison between trajectories considering therapy outcomes}

The top of Table 5 includes comparisons between trajectories considering compliance with the therapy guidelines and the presence of gambling episodes (relapses) during CBT. Trajectories T1 and T2 did not differ in these two outcomes, and they were characterized by a high proportion of participants with good compliance and a low presence of relapses. Contrarily, trajectories T3-T4-T5 featured a high proportion of participants with moderate to bad compliance with therapy guidelines and a higher proportion of relapses.

The middle of Table 5 includes comparisons between trajectories in psychopathology at the end of the CBT program. T2 obtained the lowest means compared with all the other trajectories on many SCL-90-R scales, followed by trajectories T1 and T5. The highest levels of psychopathology were found in $\mathrm{T} 3$ and $\mathrm{T} 4$.

Finally, the bottom of Table 5 contains the presence of relapses during the 12-month follow-up period. T2 registered the lower proportion of patients who reported the presence of gambling episodes during this period (5.2\%), closely followed by trajectory T1 (9.7\%). The presence of relapse for trajectory T3 (20.0\%) was statistically higher than the relapses registered for $\mathrm{T} 1$ and $\mathrm{T} 2$, and statistically lower than the presence of relapses obtained for T4 (46.2\%) and T5 (47.8\%).

\subsection{Predictive model}

Table 6 includes the results of the final multinomial logistic regressions. The final model for the sociodemographic variables retained only civil status as a significant predictor of the membership in the developmental trajectories classification. Results indicate that being single (versus being married or separated/divorced) increased the odds of being classified in trajectories 1,4 or 5 versus being classified in trajectory 2 . Regarding model 2 (which initially included patients' age, gambling related variables and psychopathological state), significant predictors retained in the final model were the number of DSM-5 criteria for GD and SCL-90R GSI scores. This model indicates that higher gambling severity at baseline (higher number of DSM-5 criteria) decreases the odds of being classified in trajectory 1 or in trajectory 2 compared with being in the other trajectories, and that worse psychopathological state (higher GSI score) decreases the odds of being classified in trajectory 2 compared with being in any 
Table 3

Comparison between trajectories in sociodemographic variables measured at the beginning of the study.

\begin{tabular}{|c|c|c|c|c|c|c|c|c|c|c|c|c|c|c|c|c|c|c|c|c|c|c|c|c|c|c|c|c|c|c|}
\hline & \multirow{2}{*}{\multicolumn{2}{|c|}{$\begin{array}{l}\mathrm{T} 1 \\
n=383\end{array}$}} & \multirow{2}{*}{\multicolumn{2}{|c|}{$\begin{array}{l}\mathrm{T} 2 \\
n=154\end{array}$}} & & \multirow{2}{*}{\multicolumn{2}{|c|}{$\begin{array}{l}\mathrm{T} 4 \\
n=13\end{array}$}} & & \multicolumn{20}{|c|}{ Pairwise comparisons } \\
\hline & & & & & & & & & & & \multicolumn{2}{|c|}{ T1vsT2 } & \multicolumn{2}{|c|}{ T1vsT3 } & \multicolumn{2}{|c|}{ T1vsT4 } & \multicolumn{2}{|c|}{ T1vsT5 } & \multicolumn{2}{|c|}{ T2vsT3 } & \multicolumn{2}{|c|}{ T2vsT4 } & \multicolumn{2}{|c|}{ T2vsT5 } & \multicolumn{2}{|c|}{ T3vsT4 } & \multicolumn{2}{|c|}{ T3vsT5 } & \multicolumn{2}{|c|}{ T4vsT5 } \\
\hline & $n$ & $\%$ & $n$ & $\%$ & $n$ & $\%$ & $n$ & $\%$ & $n$ & $\%$ & $p$ & $|d|$ & $p$ & $|d|$ & $p$ & $|d|$ & $p$ & $|d|$ & $p$ & $|d|$ & $p$ & $|d|$ & $p$ & $|d|$ & $p$ & $|d|$ & $p$ & $|d|$ & $p$ & $|d|$ \\
\hline \multicolumn{31}{|l|}{ Civil status } \\
\hline Single & 126 & 32.9 & 37 & 24.0 & 9 & 30.0 & 6 & 46.2 & 10 & 43.5 & .058 & 0.20 & .899 & 0.06 & .603 & 0.27 & .431 & 0.22 & .482 & 0.13 & .210 & 0.53 & .136 & 0.20 & .573 & 0.34 & .402 & 0.06 & .887 & 0.27 \\
\hline Married-partner & 215 & 56.1 & 104 & 67.5 & 17 & 56.7 & 6 & 46.2 & 12 & 52.2 & & 0.24 & & 0.01 & & 0.20 & & 0.08 & & 0.23 & & 0.51 & & 0.24 & & 0.21 & & 0.01 & & 0.20 \\
\hline Separated-divorce & 42 & 11.0 & 13 & 8.4 & 4 & 13.3 & 1 & 7.7 & 1 & 4.3 & & 0.09 & & 0.07 & & 0.11 & & 0.25 & & 0.16 & & 0.03 & & 0.09 & & 0.18 & & 0.07 & & 0.11 \\
\hline \multicolumn{31}{|l|}{ Education level } \\
\hline Primary & 199 & 52.0 & 89 & 57.8 & 20 & 66.7 & 6 & 46.2 & 16 & 69.6 & .442 & 0.12 & .293 & 0.30 & .528 & 0.12 & .187 & 0.37 & .662 & 0.18 & .431 & 0.23 & .407 & 0.12 & .294 & 0.42 & .676 & 0.30 & .166 & 0.12 \\
\hline Secondary & 161 & 42.0 & 58 & 37.7 & 9 & 30.0 & 7 & 53.8 & 7 & 30.4 & & 0.09 & & 0.25 & & 0.24 & & 0.24 & & 0.16 & & 0.33 & & 0.09 & & 0.50 & & 0.25 & & 0.24 \\
\hline University & 23 & 6.0 & 7 & 4.5 & 1 & 3.3 & 0 & 0.0 & 0 & 0.0 & & 0.07 & & 0.13 & & 0.36 & & 0.36 & & 0.06 & & 0.31 & & 0.07 & & 0.26 & & 0.13 & & 0.36 \\
\hline \multicolumn{31}{|l|}{ Social stat. } \\
\hline Mean-high + high & 27 & 7.0 & 8 & 5.2 & 1 & 3.3 & 0 & 0.0 & 1 & 4.3 & .453 & 0.08 & .597 & 0.17 & .591 & 0.39 & .496 & 0.12 & .635 & 0.09 & .510 & 0.33 & .288 & 0.08 & .438 & 0.26 & .640 & 0.17 & .646 & 0.39 \\
\hline Mean & 50 & 13.1 & 18 & 11.7 & 2 & 6.7 & 3 & 23.1 & 3 & 13.0 & & 0.04 & & 0.22 & & 0.26 & & 0.00 & & 0.17 & & 0.30 & & 0.04 & & 0.52 & & 0.22 & & 0.26 \\
\hline Mean-low & 132 & 34.5 & 64 & 41.6 & 11 & 36.7 & 4 & 30.8 & 5 & 21.7 & & 0.15 & & 0.05 & & 0.08 & & 0.29 & & 0.10 & & 0.23 & & 0.15 & & 0.12 & & 0.05 & & 0.08 \\
\hline Low & 174 & 45.4 & 64 & 41.6 & 16 & 53.3 & 6 & 46.2 & 14 & 60.9 & & 0.08 & & 0.16 & & 0.01 & & 0.31 & & 0.24 & & 0.09 & & 0.08 & & 0.14 & & 0.16 & & 0.01 \\
\hline \multicolumn{31}{|l|}{ Employment } \\
\hline Unemployed & 139 & 36.3 & 63 & 40.9 & 12 & 40.0 & 5 & 38.5 & 10 & 43.5 & .318 & 0.09 & .685 & 0.08 & .873 & 0.04 & .487 & 0.15 & .926 & 0.02 & .863 & 0.05 & .815 & 0.09 & .925 & 0.03 & .799 & 0.08 & .769 & 0.04 \\
\hline \multicolumn{31}{|l|}{ Origin } \\
\hline Immigrant & 9 & 2.3 & 6 & 3.9 & 0 & 0.0 & 0 & 0.0 & 2 & 8.7 & .325 & 0.09 & .396 & 0.22 & .576 & 0.22 & .069 & 0.28 & .272 & 0.28 & .469 & 0.28 & .301 & 0.09 & - & - & .100 & 0.22 & .274 & 0.22 \\
\hline
\end{tabular}

Note.

Bold: significant comparison (.05 level)

${ }^{\dagger}$ Bold: effect size in the moderate $(|d|>0.50)$ to good range $(|d|>0.80)$. 
Comparison between trajectories in clinical state (gambling variables, psychopathology and personality) at baseline.

\begin{tabular}{|c|c|c|c|c|c|c|c|c|c|c|c|c|c|c|c|c|c|c|c|c|c|c|c|c|c|c|c|c|c|c|}
\hline & \multirow{2}{*}{\multicolumn{2}{|c|}{$\frac{\mathrm{T} 1}{n=383}$}} & \multirow{2}{*}{\multicolumn{2}{|c|}{$\frac{\mathrm{T} 2}{n=154}$}} & \multirow{2}{*}{\multicolumn{2}{|c|}{$\frac{\mathrm{T} 3}{n=30}$}} & \multirow{2}{*}{\multicolumn{2}{|c|}{$\frac{\mathrm{T} 4}{n=13}$}} & \multirow{2}{*}{\multicolumn{2}{|c|}{$\frac{\mathrm{T} 5}{n=23}$}} & \multicolumn{20}{|c|}{ Pairwise comparisons } \\
\hline & & & & & & & & & & & \multicolumn{2}{|c|}{ T1vsT2 } & \multicolumn{2}{|c|}{ T1vsT3 } & \multicolumn{2}{|c|}{ T1vsT4 } & \multicolumn{2}{|c|}{ T1vsT5 } & \multicolumn{2}{|c|}{ T2vsT3 } & \multicolumn{2}{|c|}{ T2vsT4 } & \multicolumn{2}{|c|}{ T2vsT5 } & \multicolumn{2}{|c|}{ T3vsT4 } & \multicolumn{2}{|c|}{ T3vsT5 } & \multicolumn{2}{|c|}{ T4vsT5 } \\
\hline & $M$ & $S D$ & $M$ & $S D$ & $M$ & $S D$ & $M$ & $S D$ & $M$ & $S D$ & $p$ & $|d|$ & $p$ & $|d|$ & $p$ & $|d|$ & $p$ & $|d|$ & $p$ & $|d|$ & $p$ & $|d|$ & $p$ & $|d|$ & $p$ & $|d|$ & $p$ & $|d|$ & $p$ & $|d|$ \\
\hline Gambling variables & & & & & & & & & & & & & & & & & & & & & & & & & & & & & & \\
\hline Age (years-old) & 44.4 & 13.4 & 45.9 & 14.1 & 44.4 & 12.2 & 43.2 & 8.9 & 42.2 & 15.8 & .262 & 0.11 & .986 & 0.00 & .757 & 0.10 & .442 & 0.15 & .580 & 0.11 & .502 & 0.22 & .224 & 0.25 & .801 & 0.11 & .560 & 0.16 & .822 & 0.08 \\
\hline Age of onset (years-old) & 29.4 & 11.4 & 31.5 & 12.3 & 29.8 & 10.9 & 31.0 & 9.0 & 31.8 & 13.7 & .067 & 0.28 & .872 & 0.03 & .629 & 0.16 & .360 & 0.19 & .465 & 0.15 & .881 & 0.05 & .910 & 0.02 & .752 & 0.12 & .542 & 0.16 & .844 & 0.07 \\
\hline Duration (years) & 15.4 & 8.1 & 14.3 & 8.1 & 15.2 & 7.0 & 12.9 & 8.9 & 10.5 & 6.5 & .165 & 0.13 & .868 & 0.03 & .267 & 0.29 & .006 & 0.68 & .610 & 0.11 & .539 & 0.17 & $.038^{*}$ & 0.53 & .399 & 0.28 & $.041^{*}$ & 0.70 & .386 & 0.31 \\
\hline DSM-5 total criteria & 7.74 & 1.08 & 4.62 & 1.23 & 7.20 & 1.61 & 7.08 & 1.50 & 7.00 & 1.71 & $.001 *$ & 2.70 & $.016 *$ & 0.40 & .048 & 0.51 & .004 & 0.52 & $.001^{*}$ & 1.81 & .001 & 1.80 & .001 & $\mathbf{1 . 6 0}$ & .755 & 0.08 & .544 & 0.12 & .852 & 0.05 \\
\hline SOGS-total score & 11.6 & 2.5 & 8.5 & 2.3 & 11.4 & 3.4 & 11.3 & 3.1 & 10.7 & 2.1 & $.001 *$ & 1.29 & .707 & 0.06 & .700 & 0.10 & .083 & 0.41 & $.001 *$ & 1.00 & $.001^{*}$ & 1.01 & $.001^{*}$ & 0.98 & .911 & 0.03 & .277 & 0.27 & .446 & 0.25 \\
\hline & $n$ & $\%$ & $n$ & $\%$ & $n$ & $\%$ & $n$ & $\%$ & $n$ & $\%$ & $p$ & $|d|$ & $p$ & $|d|$ & $p$ & $|d|$ & $p$ & $|d|$ & $p$ & $|d|$ & $p$ & $|d|$ & $p$ & $|d|$ & $p$ & $|d|$ & $p$ & $|d|$ & $p$ & $|d|$ \\
\hline $\begin{array}{l}\text { Debts due to } \\
\text { gambling (yes) }\end{array}$ & 185 & 48.3 & 53 & 34.4 & 17 & 56.7 & 10 & 76.9 & 10 & 43.5 & $.003^{\circ}$ & 0.28 & .377 & 0.17 & .042 & 0.62 & .653 & 0.10 & .022 & 0.52 & .002 & 0.95 & .397 & 0.19 & .207 & 0.44 & .341 & 0.27 & $.048^{*}$ & 0.73 \\
\hline Gambling & & & & & & & & & & & & & & & & & & & & & & & & & & & & & & \\
\hline Non-strategic & 302 & 78.9 & 134 & 87.0 & 24 & 80.0 & 11 & 84.6 & 17 & 73.9 & .080 & 0.22 & .818 & 0.03 & .837 & 0.15 & .673 & 0.12 & .354 & 0.19 & .800 & 0.07 & .134 & 0.34 & .938 & 0.12 & .871 & 0.14 & .759 & 0.27 \\
\hline Strategic & 51 & 13.3 & 14 & 9.1 & 3 & 10.0 & 1 & 7.7 & 3 & 13.0 & & 0.13 & & 0.10 & & 0.18 & & 0.01 & & 0.03 & & 0.05 & & 0.13 & & 0.08 & & 0.10 & & 0.18 \\
\hline Both & 30 & 7.8 & 6 & 3.9 & 3 & 10.0 & 1 & 7.7 & 3 & 13.0 & & 0.17 & & 0.08 & & 0.01 & & 0.17 & & 0.24 & & 0.16 & & 0.33 & & 0.08 & & 0.10 & & 0.18 \\
\hline Psychopath. (SCL-90R) & & & & & & & & & & & & & & & & & & & & & & & & & & & & & & \\
\hline Somatization & 1.01 & 0.76 & 0.40 & 0.41 & 0.82 & 0.73 & 0.92 & 0.58 & 0.86 & 0.70 & $.001 *$ & 1.00 & .156 & 0.25 & .651 & 0.14 & .287 & 0.21 & $.003^{*}$ & $0.71^{+}$ & .015 & 1.03 & $.003^{*}$ & 0.80 & .694 & 0.14 & .861 & 0.05 & .805 & 0.10 \\
\hline Obsessive/comp. & 1.22 & 0.71 & 0.49 & 0.47 & 0.99 & 0.73 & 1.33 & 0.70 & 1.14 & 0.91 & .001 & 1.22 & .085 & 0.31 & .591 & 0.16 & .583 & 0.10 & .001 & 0.82 & $.001 *$ & 1.41 & $.001^{*}$ & 0.90 & .159 & 0.53 & .436 & 0.18 & .442 & 0.23 \\
\hline $\begin{array}{c}\text { Interpersonal } \\
\text { sensitivity }\end{array}$ & 1.10 & 0.73 & 0.34 & 0.37 & 0.90 & 0.75 & 1.21 & 0.66 & 0.86 & 0.69 & .001 & 1.33 & .112 & 0.28 & .588 & 0.16 & .076 & 0.35 & .001 & 0.96 & $.001^{*}$ & $1.63^{+}$ & .001 & 0.93 & .180 & 0.44 & .803 & 0.06 & .135 & 0.53 \\
\hline Depressive & 1.67 & 0.81 & 0.70 & 0.48 & 1.49 & 0.71 & 1.64 & 0.92 & 1.15 & 0.73 & $.001^{*}$ & $1.46^{\dagger}$ & .203 & 0.24 & .882 & 0.04 & $.001^{*}$ & 0.67 & $.001^{*}$ & 1.29 & $.001^{*}$ & 1.28 & $.006 *$ & 0.74 & .566 & 0.18 & .109 & 0.46 & $.047^{*}$ & $\mathbf{0 . 5 8}$ \\
\hline Anxiety & 1.09 & 0.71 & 0.37 & 0.33 & 0.99 & 0.81 & 1.24 & 0.69 & 0.79 & 0.73 & $.001 *$ & 1.28 & .440 & 0.13 & .445 & 0.21 & $.033^{*}$ & 0.41 & $.001 *$ & 1.00 & $.001 *$ & 1.59 & $.004 *$ & 0.73 & .280 & 0.33 & .273 & 0.26 & .049 & 0.63 \\
\hline Hostility & 0.96 & 0.75 & 0.38 & 0.40 & 0.93 & 0.88 & 1.11 & 0.72 & 0.71 & 0.75 & $.001 *$ & 0.97 & .794 & 0.04 & .493 & 0.19 & .084 & 0.34 & $.001^{*}$ & 0.80 & .001 & 1.24 & $.033^{*}$ & 0.54 & .464 & 0.22 & .254 & 0.27 & .113 & 0.54 \\
\hline Phobic anxiety & 0.45 & 0.57 & 0.12 & 0.27 & 0.44 & 0.69 & 0.71 & 0.78 & 0.47 & 0.80 & $.001 *$ & 0.74 & .958 & 0.01 & .105 & 0.39 & .886 & 0.02 & .003 & 0.62 & $.001 *$ & 1.02 & .004 & 0.58 & .155 & 0.37 & .884 & 0.03 & .205 & 0.31 \\
\hline Paranoid ideation & 0.94 & 0.73 & 0.37 & 0.40 & 0.85 & 0.78 & 1.02 & 0.79 & 0.57 & 0.56 & $.001^{*}$ & 0.99 & .468 & 0.12 & .726 & 0.09 & $.007^{*}$ & 0.58 & $.001^{*}$ & 0.78 & .002 & 1.03 & .177 & 0.41 & .483 & 0.21 & .123 & 0.42 & .042 & $\mathbf{0 . 6 5}$ \\
\hline Psychotic & 1.03 & 0.70 & 0.33 & 0.33 & 0.86 & 0.69 & 0.95 & 0.71 & 0.80 & 0.68 & $.001 *$ & 1.28 & .179 & 0.24 & .662 & 0.12 & .083 & 0.34 & $.001 *$ & 0.99 & .002 & 1.11 & $.001 *$ & 0.87 & .716 & 0.12 & .697 & 0.10 & .514 & 0.21 \\
\hline GSI score & 1.14 & 0.60 & 0.44 & 0.29 & 0.99 & 0.63 & 1.20 & 0.61 & 0.88 & 0.61 & .001 & 1.50 & .157 & 0.24 & .737 & 0.09 & $.023^{*}$ & 0.44 & .001 & 1.13 & $.001 *$ & 1.61 & $.001^{*}$ & 0.93 & .285 & 0.33 & .448 & 0.19 & .106 & 0.53 \\
\hline PST score & 51.3 & 17.6 & 25.0 & 13.7 & 46.3 & 18.3 & 55.5 & 19.4 & 39.2 & 17.0 & .001 & 1.67 & .113 & 0.28 & .383 & 0.22 & $.001 *$ & $0.70^{\dagger}$ & $.001 *$ & 1.32 & $.001 *$ & 1.82 & $.001 *$ & 0.92 & .100 & $0.50^{\dagger}$ & .125 & 0.40 & .005 & 0.89 \\
\hline PSDI score & 1.92 & 0.53 & 1.55 & 0.42 & 1.88 & 0.51 & 1.85 & 0.61 & 1.85 & 0.74 & $.001 *$ & 0.78 & .666 & 0.08 & .666 & 0.12 & .541 & 0.11 & .002 & 0.70 & .049 & 0.58 & $.009^{*}$ & 0.51 & .893 & 0.04 & .868 & 0.04 & .998 & 0.00 \\
\hline Personality (TCI-R) & & & & & & & & & & & & & & & & & & & & & & & & & & & & & & \\
\hline Novelty seeking & 110.1 & 14.0 & 102.0 & 14.1 & 110.8 & 12.7 & 106.7 & 10.7 & 104.8 & 14.5 & $.001^{*}$ & 0.58 & .806 & 0.05 & .401 & 0.28 & .082 & 0.37 & .002 & 0.66 & .260 & 0.38 & .377 & 0.20 & .392 & 0.35 & .129 & 0.44 & .705 & 0.15 \\
\hline Harm avoidance & 102.3 & 16.5 & 92.5 & 15.5 & 104.2 & 16.4 & 107.4 & 15.8 & 103.9 & 13.6 & $.001 *$ & 0.61 & .527 & 0.12 & .278 & 0.32 & .644 & 0.11 & $.001 *$ & 0.73 & .002 & 0.95 & .002 & $0.78^{\dagger}$ & .567 & 0.20 & .942 & 0.02 & .545 & 0.24 \\
\hline Reward dependence & 97.5 & 14.8 & 103.2 & 14.1 & 100.4 & 13.8 & 97.0 & 17.0 & 94.5 & 14.9 & .001 & 0.40 & .301 & 0.20 & .915 & 0.03 & .364 & 0.20 & .340 & 0.20 & .157 & 0.40 & .010 & 0.60 & .501 & 0.22 & .159 & 0.41 & .640 & 0.15 \\
\hline Persistence & 108.8 & 19.9 & 110.1 & 19.2 & 106.5 & 19.3 & 99.4 & 22.8 & 101.3 & 18.3 & .491 & 0.07 & .550 & 0.12 & .105 & 0.44 & .082 & 0.39 & .369 & 0.19 & $.071^{*}$ & 0.51 & $.048^{*}$ & $0.47^{\dagger}$ & .294 & 0.34 & .346 & 0.28 & .793 & 0.09 \\
\hline Self-directedness & 123.8 & 18.7 & 142.9 & 17.5 & 125.9 & 19.1 & 128.2 & 13.7 & 125.3 & 23.9 & $.001 *$ & 1.06 & .550 & 0.11 & .418 & 0.27 & .701 & 0.07 & $.001 *$ & 0.93 & .009 & 0.94 & $.001^{*}$ & 0.84 & .722 & 0.14 & .912 & 0.03 & .669 & 0.15 \\
\hline Cooperativeness & 130.2 & 15.7 & 139.0 & 13.3 & 129.1 & 16.0 & 133.5 & 16.7 & 130.8 & 16.0 & $.001 *$ & 0.60 & .708 & 0.07 & .463 & 0.20 & .872 & 0.03 & $.001 *$ & 0.67 & .228 & 0.36 & $.018^{*}$ & 0.56 & .402 & 0.27 & .703 & 0.10 & .616 & 0.17 \\
\hline Self-Transcendence & 64.5 & 14.8 & 61.6 & 14.3 & 62.9 & 13.8 & 64.3 & 17.0 & 59.6 & 16.8 & .058 & 0.20 & .594 & 0.11 & .963 & 0.01 & .134 & 0.31 & .657 & 0.10 & .550 & 0.17 & .552 & 0.13 & .795 & 0.09 & .424 & 0.22 & .380 & 0.28 \\
\hline
\end{tabular}



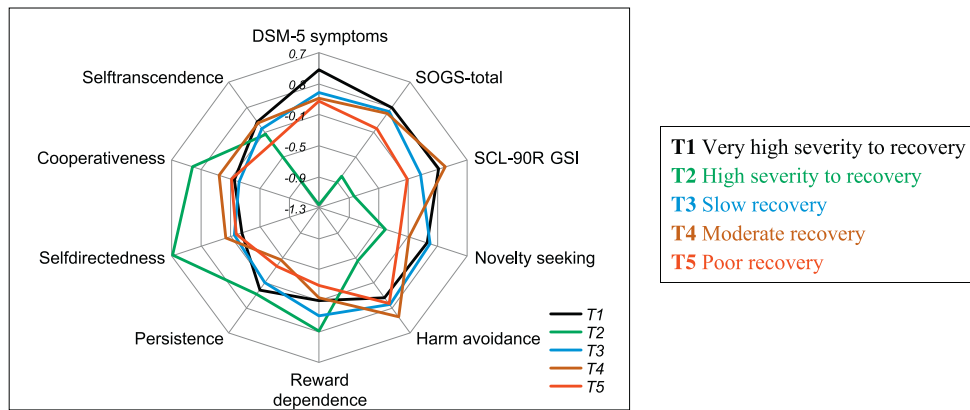

Fig. 2. Radar chart with the main psychological variables differing between the trajectories (at baseline) $(n=603)$.

other trajectory. Finally, model 3 (which initially included all the TCI-R scores), retained novelty seeking (higher levels predict lower odds of being in trajectory 2 compared to trajectories 1 and 3), harm avoidance (higher levels predict lower odds of being in trajectory 2 compared to being in trajectories 1, 3 and 4) and selfdirectedness (higher levels predict higher odds of being in trajectory 2 compared to being in trajectories 1 and 5 ) as significant predictors.

\section{Discussion}

This study used LCGA to obtain an empirical classification for a sample of patients who met clinical criteria for GD, based on gambling severity during the 12 months following a CBT program. SOGS total score was selected as a measure of change in the GD severity because it provides a wider range of scores based on scalar measures and this attribute statistically facilitated the identification of developmental trajectories with better fitting. T1 and T2 included the largest number of participants (in total $n=537,89 \%$ of the sample), and were defined by high to severe gambling severity at baseline and good progress to recovery during the follow-up. Trajectory T3 $(n=30,5.0 \%)$ included also participants with initial severe affectation and slow evolution to recovery. T4 and T5 included the least number of participants (in total $n=36,6 \%$ ), characterized by severe baseline gambling severity and poor progress during the follow-up period.

The trajectories obtained discriminative capacity in terms of psychopathology levels, personality traits at baseline, the degree of compliance with the therapy guidelines during the CBT program, and the presence of relapses during CBT and during the 12-month follow-up. T3 included patients with a severe baseline psychopathology, but with good progress during recovery (although these clinical improvements were slowly obtained). These patients may have benefited from a more intense treatment plan in order to attain complete gambling abstinence more quickly (for example, treatment plans with a greater number of sessions). Trajectories T4 and T5 had the lowest duration of the gambling problem, high psychopathology at baseline and low scores in reward dependence and persistence. They also obtained the highest proportion of participants with poor compliance during treatment and relapses were the highest for these groups. As a whole, these results seem consistent with a recent systematic review highlighting the pretreatment predictors of short- and long-term GD treatment outcomes. This review found shows that less psychopathology at intake (mainly depression and anxiety levels) were the most consistent predictors of success after treatment across multiple time points, followed by older age, lower gambling severity at intake, education levels, and personality traits [11].

Another important aspect to consider is the course of the disorder. The results of the present study suggest that shorter GD duration is associated with poorer treatment outcomes, as described in previous studies $[16,58]$. A possible explanatory hypothesis to these findings would be related to the awareness of disorder and motivation to deal with the gambling problem [59]. It could be that the patients with the worse therapeutic evolution had undergone less negative consequences for their gambling behavior and, therefore, had less intrinsic motivation to change. It is possible that the goal of our program to obtain complete abstinence from all types of gambling may be too ambitious for patients with shorter GD duration $[60,61]$. In addition, taking into account that therapeutic goals may change throughout treatment. In this vein, Stea, Hodgins \& Fung [61] showed that half of subjects following a treatment program based on a brief motivational intervention modified their therapeutic goals as therapy progressed. The majority began the recovery process by assuming definitive abstinence from all types of gambling, however later on, more than 25\% expressed their willingness to give up their problematic type of gambling, $10 \%$ bet in a controlled manner and only $20 \%$ continued with the decision to abandon all types of gambling. In fact, patients often return to gambling, to a greater or lesser extent, after having undergone treatment for their disorder and, more specifically, at 12 months of follow-up [62]. Although this does not always means therapy was a failure or a worsening of their gambling problem [14]. Also at a 12-month follow-up, another study identified that $41.6 \%$ of subjects treated with an inpatient treatment program maintained complete abstinence from all types of gambling, while $29.2 \%$ of patients still met diagnostic criteria for GD, although another $29.2 \%$ still had some form of gambling, but did not meet diagnostic criteria [14]. Considering this issue, some studies have explored the effectiveness of programs oriented to controlled gambling [60,61,63-66]. Actually, it seems that in the community, most individuals who have had gambling problems end up recovering without having totally abstained from gambling behavior, during the process [25]. Therefore, although abstinence is the most common therapeutic goal in treatment programs [67], it could be timely to explore other alternatives such as controlled gambling, in the context of personalized therapeutic approaches, discussing with the patient their own goals and objectives [14,68]. However, focusing on T4 and $\mathrm{T} 5$, it is necessary to bear in mind that other associated factors may be personality traits such as lower reward dependence and low persistence. These traits could be defined as the presence of less interest in pleasing others, social withdrawal, detachment and distance in interpersonal interactions [11-13]. Likewise, they may show a tendency to easily abandon their goals at the slightest setback and or sign of frustration. Taking all these results together, we could consider that, perhaps, these patients could benefit from motivational interventions, as the systematic review and metaanalysis by Yakovenko et al [69] demonstrated in terms of improvement of gambling problems at 1, 3 and 12 months of follow-up. Therefore, motivational interviews could help to improve their awareness of their condition, to make their 
Table 5

Comparison between trajectories for therapy outcomes.

\begin{tabular}{|c|c|c|c|c|c|c|c|c|c|c|c|c|c|c|c|c|c|c|c|c|c|c|c|c|c|c|c|c|c|c|}
\hline \multirow[b]{3}{*}{ During therapy } & \multirow{2}{*}{\multicolumn{2}{|c|}{$\begin{array}{l}\mathrm{T} 1 \\
n=383\end{array}$}} & \multirow{2}{*}{\multicolumn{2}{|c|}{$\begin{array}{l}\mathrm{T} 2 \\
n=154\end{array}$}} & \multirow{2}{*}{\multicolumn{2}{|c|}{$\frac{\mathrm{T} 3}{n=30}$}} & \multirow{2}{*}{\multicolumn{2}{|c|}{$\frac{\mathrm{T} 4}{n=13}$}} & \multirow{2}{*}{\multicolumn{2}{|c|}{$\frac{\mathrm{T} 5}{n=23}$}} & \multicolumn{20}{|c|}{ Pairwise comparisons } \\
\hline & & & & & & & & & & & \multicolumn{2}{|c|}{ T1vsT2 } & \multicolumn{2}{|c|}{ T1vsT3 } & \multicolumn{2}{|c|}{ T1vsT4 } & \multicolumn{2}{|c|}{ T1vsT5 } & \multicolumn{2}{|c|}{ T2vsT3 } & \multicolumn{2}{|c|}{ T2vsT4 } & \multicolumn{2}{|c|}{ T2vsT5 } & \multicolumn{2}{|c|}{ T3vsT4 } & \multicolumn{2}{|c|}{ T3vsT5 } & \multicolumn{2}{|c|}{ T4vsT5 } \\
\hline & $n$ & $\%$ & $n$ & $\%$ & $n$ & $\%$ & $n$ & $\%$ & $n$ & $\%$ & $p$ & $|d|$ & $p$ & $|d|$ & $p$ & $|d|$ & $p$ & $|d|$ & $p$ & $|d|$ & $\bar{p}$ & $|d|$ & $p$ & $|d|$ & $p$ & $|d|$ & $p$ & $|d|$ & $p$ & $|d|$ \\
\hline \multicolumn{31}{|l|}{${ }^{1}$ Compliance } \\
\hline Good & 296 & 77.3 & 125 & 81.2 & 13 & 43.3 & 8 & 61.5 & 14 & 60.9 & .606 & 0.10 & .001 & 0.74 & .039 & 0.35 & .119 & 0.36 & $.001 *$ & 0.85 & .041 & 0.44 & .048 & $0.51^{+}$ & .504 & 0.37 & .418 & 0.36 & .780 & 0.01 \\
\hline Moderate & 76 & 19.8 & 25 & 16.2 & 12 & 40.0 & 3 & 23.1 & 7 & 30.4 & & 0.09 & & 0.52 & & 0.08 & & 0.25 & & 0.55 & & 0.17 & & 0.34 & & 0.37 & & 0.20 & & 0.17 \\
\hline Bad & 11 & 2.9 & 4 & 2.6 & 5 & 16.7 & 2 & 15.4 & 2 & 8.7 & & 0.02 & & 0.53 & & 0.52 & & 0.25 & & 0.49 & & 0.51 & & 0.27 & & 0.03 & & 0.24 & & 0.21 \\
\hline${ }^{2}$ Relapses & 53 & 13.8 & 18 & 11.7 & 16 & 53.3 & 6 & 46.2 & 8 & 34.8 & .506 & 0.06 & .001 & 0.92 & $.001^{*}$ & $0.75^{\dagger}$ & .006 & $\mathbf{0 . 5 0}$ & $.001^{*}$ & 0.99 & .001 & $0.82^{\dagger}$ & .004 & 0.57 & .665 & 0.14 & .179 & 0.38 & .501 & 0.23 \\
\hline Post-therapy & $M$ & $S D$ & M & $S D$ & $M$ & $S D$ & $M$ & $S D$ & $M$ & $S D$ & $p$ & $|d|$ & $p$ & $|d|$ & $p$ & $|d|$ & $p$ & $|d|$ & $p$ & $|d|$ & $p$ & $|d|$ & $p$ & $|d|$ & $p$ & $|d|$ & $p$ & $|d|$ & $p$ & $|d|$ \\
\hline $\begin{array}{l}\text { SCL-90R } \\
\text { Somatization }\end{array}$ & 0.46 & 0.54 & 0.24 & 0.33 & 0.59 & 0.54 & 0.76 & 0.76 & 0.51 & 0.52 & .001 & 0.51 & .151 & 0.25 & $.035^{\circ}$ & 0.54 & .653 & 0.09 & .001 & 0.79 & .001 & 0.88 & .019 & 0.62 & .330 & 0.25 & .536 & 0.16 & .155 & 0.38 \\
\hline $\begin{array}{l}\text { SCL-90R Obsessive/ } \\
\text { comp. }\end{array}$ & 0.54 & 0.59 & 0.25 & 0.34 & 0.77 & 0.80 & 0.83 & 0.63 & 0.65 & 0.58 & $.001^{*}$ & 0.62 & .029 & 0.32 & $.046^{*}$ & 0.56 & .363 & 0.19 & $.001 *$ & 0.85 & .001 & 1.16 & $.001 *$ & 0.86 & .753 & 0.08 & .442 & 0.17 & .360 & 0.29 \\
\hline $\begin{array}{l}\text { SCL-90R Interp. } \\
\text { sensitivity }\end{array}$ & 0.46 & 0.57 & 0.21 & 0.29 & 0.61 & 0.75 & 0.66 & 0.58 & 0.53 & 0.44 & $.001^{*}$ & 0.55 & .125 & 0.23 & .185 & 0.34 & .587 & 0.12 & .001 & 0.70 & $.003^{*}$ & 0.96 & .009 & 0.84 & .802 & 0.06 & .540 & 0.15 & .466 & 0.26 \\
\hline $\begin{array}{l}\text { SCL-90R } \\
\text { Depressive }\end{array}$ & 0.61 & 0.64 & 0.31 & 0.37 & 0.99 & 0.81 & 0.86 & 0.70 & 0.74 & 0.62 & $.001^{*}$ & 0.58 & .001 & $0.52^{\dagger}$ & .135 & 0.37 & .325 & 0.20 & $.001 *$ & 1.08 & .001 & 1.00 & $.001 *$ & 0.85 & .525 & 0.17 & .138 & 0.34 & .556 & 0.19 \\
\hline SCL-90R Anxiety & 0.37 & 0.49 & 0.17 & 0.26 & 0.56 & 0.65 & 0.67 & 0.58 & 0.51 & 0.47 & $.001 *$ & 0.52 & $.027^{*}$ & 0.33 & .021 & 0.55 & .171 & 0.29 & $.001^{*}$ & 0.80 & .001 & 1.12 & $.001^{*}$ & 0.90 & .486 & 0.17 & .673 & 0.10 & .317 & 0.31 \\
\hline SCL-90R Hostility & 0.37 & 0.53 & 0.17 & 0.30 & 0.66 & 0.90 & 0.73 & 0.74 & 0.36 & 0.41 & .001 & 0.46 & .003 & 0.40 & .013 & 0.56 & .958 & 0.01 & $.001^{*}$ & 0.73 & .001 & 0.99 & .049 & 0.53 & .682 & 0.08 & $.039^{\prime}$ & $0.53^{\dagger}$ & .041 & $\mathbf{0 . 6 1}$ \\
\hline $\begin{array}{l}\text { SCL-90R Phobic } \\
\text { anxiety }\end{array}$ & 0.19 & 0.42 & 0.10 & 0.25 & 0.29 & 0.58 & 0.43 & 0.48 & 0.25 & 0.41 & .012 & 0.28 & .209 & 0.19 & $.033^{*}$ & 0.53 & .478 & 0.15 & $.016^{*}$ & 0.60 & .004 & 0.88 & .048 & $\mathbf{0 . 5 6}$ & .273 & 0.27 & .768 & 0.06 & .202 & 0.39 \\
\hline $\begin{array}{l}\text { SCL-90R Paranoid } \\
\text { ideation }\end{array}$ & 0.46 & 0.55 & 0.21 & 0.31 & 0.69 & 1.01 & 0.55 & 0.60 & 0.36 & 0.44 & $.001 *$ & 0.57 & $.027^{*}$ & 0.28 & .563 & 0.15 & .355 & 0.22 & $.0011^{*}$ & 0.64 & $.027^{*}$ & $0.71^{\dagger}$ & .226 & 0.38 & .437 & 0.16 & $.026 *$ & 0.51 & .296 & 0.37 \\
\hline SCL-90R Psychotic & 0.35 & 0.51 & 0.13 & 0.22 & 0.55 & 0.63 & 0.58 & 0.57 & 0.47 & 0.48 & $.001^{*}$ & 0.57 & .026 & 0.35 & $.046 *$ & 0.43 & .255 & 0.23 & $.001 *$ & 0.89 & .001 & 1.06 & $.001^{*}$ & 0.91 & .831 & 0.05 & .523 & 0.15 & .472 & 0.22 \\
\hline SCL-90R GSI score & 0.46 & 0.48 & 0.22 & 0.24 & 0.68 & 0.66 & 0.74 & 0.55 & 0.53 & 0.42 & $.001^{*}$ & 0.64 & $.007 *$ & 0.39 & $.023^{*}$ & 0.55 & .470 & 0.16 & $.001^{*}$ & 0.95 & $.001 *$ & 1.23 & $.002^{*}$ & 0.91 & .697 & 0.09 & .208 & 0.28 & .168 & $\mathbf{0 . 6 3}$ \\
\hline SCL-90R PST score & 25.79 & 19.77 & 14.23 & 15.64 & 34.20 & 22.98 & 40.15 & 23.64 & 29.14 & 18.83 & .001 & 0.65 & .020 & 0.39 & $.008 *$ & 0.66 & .424 & 0.17 & .001 & 1.02 & .001 & 1.29 & $.001^{*}$ & 0.86 & .347 & 0.26 & .344 & 0.24 & .049 & $\mathbf{0 . 5 2}$ \\
\hline SCL-90R PSDI score & 1.43 & 0.48 & 1.37 & 0.45 & 1.64 & 0.53 & 1.53 & 0.46 & 1.49 & 0.40 & .250 & 0.12 & .019 & 0.41 & .459 & 0.21 & .539 & 0.14 & .005 & 0.54 & .265 & 0.34 & .277 & 0.28 & .474 & 0.22 & .267 & 0.31 & .833 & 0.08 \\
\hline During follow-up & $n$ & $\%$ & $n$ & $\%$ & $n$ & $\%$ & $n$ & $\%$ & $n$ & $\%$ & $p$ & $|d|$ & $p$ & $|d|$ & $p$ & $|d|$ & $p$ & $|d|$ & $p$ & $|d|$ & $p$ & $|d|$ & $p$ & $|d|$ & $p$ & $|d|$ & $p$ & $|d|$ & $p$ & $|d|$ \\
\hline${ }^{2}$ Relapses & 37 & 9.7 & 8 & 5.2 & 6 & 20.0 & 6 & 46.2 & 11 & 47.8 & .140 & 0.17 & .001 & 0.29 & $.001^{*}$ & $\mathbf{0 . 8 9}$ & .005 & 0.93 & .001 & 0.54 & .001 & $\mathbf{1 . 0 6} \mathbf{b}^{\dagger}$ & $.001^{*}$ & 1.10 & $.049^{*}$ & 0.58 & $.031^{*}$ & 0.61 & .923 & 0.03 \\
\hline
\end{tabular}


therapeutic guidelines more flexible, and to set aims other than definitive abstinence. In addition, these patients could also be treated adding complementary interventions aimed at increasing the capacity for emotion regulation in order to better manage feelings of frustration, anger, anger, anxiety or sadness. Previous studies have shown the association between emotion regulation deficits and lack of persistence in treatment in subjects with substance use [70]. Furthermore, emotion regulation is closely related to decision making [71] and gambling disorder patients present marked deficits in decision making, as in the case of alcohol and substance use disorders [72]. Finally, previous research has demonstrated the usefulness of combining standard CBT programs with treatments based on new technologies, such as serious games designed to improve emotion regulation strategies and self-control capacity [73-75], as well as in gambling disorder [76,77]. Another alternative for these type of patients with poor response to treatment, as in the case of the patients grouped in T4 and T5, could be to include neurocognitive stimulation protocols aimed at training executive functions $[78,79]$. It should be borne in mind that perhaps they may even benefit from carrying out all these therapeutic strategies in individual treatment programs instead of in a group format. In sum, they may feel more comfortable in a treatment more tailored to their needs and without having to establish social relationships with the rest of the patients participating in the same group treatment program.

This work should be evaluated within the context of several limitations. First, only the 12 months of follow-up after CBT treatment was covered, and therefore there is no way of knowing the extent to which the developmental trajectories may persist over time. Second, the presence of dropout during the study was $34.2 \%$. It must be highlighted, however, that the developmental trajectories have been estimated with a full information method, which does not replace or impute missing data, but which handles incomplete information within the analysis using all the available information in the data set. This procedure has demonstrated good reliability/validity to produce unbiased parameter estimates for missing data in models from LCGA to structural equations procedures. This study has obtained empirical latent classes based on GD severity (like many longitudinal studies, which generate the developmental trajectories based on the evolution of a concrete measure) $(232,426)$. Still, it would be very appropriate for future research to extend the generation of the groups by incorporating time-invariant and time-variant features.

\section{Funding sources}

We thank CERCA Programme/Generalitat de Catalunya for institutional support. This manuscript and research was supported by grants from the Ministerio de Economía y Competitividad (PSI2015-68701-R), Instituto de Salud Carlos III (ISCIII) (FIS PI14/00290 and Funded by Delegación del Gobierno para el Plan Nacional sobre Drogas (2017/I067) and co-funded by FEDER funds/European Regional Development Fund (ERDF), a way to build Europe. CIBERObn and CIBERSAM are both initiatives of ISCIII. The funders had no role in the study design, data collection and analysis, decision to publish, or preparation of the manuscript. GMB was supported by a predoctoral AGAUR grant (2018 FI_B2 00,174), grant co-funded by the European Social Fund (ESF) "ESF", investing in your future. With the support of the Secretariat for Universities and Research of the Ministry of Business and Knowledge of the Government of Catalonia. TMM and CVA are supported by a predoctoral Grant of the Ministerio de Educación, Cultura y Deporte (FPU16/02087; FPU16/01453). 


\section{Declarations of interest}

None.

\section{References}

[1] American Psychiatric Association. Diagnostic and statistical manual of mental disorders DSM-5. Washington DC: American Psychiatric Association; 2013.

[2] Yakovenko I, Hodgins DC, el-Guebaly N, Casey DM, Currie SR, Smith GJ, et al. Cognitive distortions predict future gambling involvement. Int Gambl Stud 2016;16(2):175-92.

[3] Dowling NA, Merkouris SS, Greenwood CJ, Oldenhof E, Toumbourou JW, Youssef GJ. Early risk and protective factors for problem gambling: a systematic review and meta-analysis of longitudinal studies. Clin Psychol Rev 2017;51:109-24.

[4] Petry NM, Ginley MK, Rash CJ. A systematic review of treatments for problem gambling. Psychol Addict Behav 2017;31(8):951-61.

[5] Petry NM, Zajac K, Ginley MK. Behavioral addictions as mental disorders: to be or not to be? Annu Rev Clin Psychol 2018;14(1):399-423.

[6] Yau YHC, Potenza MN. Gambling disorder and other behavioral addictions. Harv Rev Psychiatry 2015;23(2):134-46.

[7] Maynard BR, Wilson AN, Labuzienski E, Whiting SW. Mindfulness-based approaches in the treatment of disordered gambling: a systematic review and meta-analysis. Res Soc Work Pract 2018;28(3):348-62.

[8] Muench HM, Goslar M, Hofmann SG, Leibetseder M, Laireiter A-R. Efficacy of face-to-face versus self-guided treatments for disordered gambling: a metaanalysis. J Behav Addict 2017;6(2):142-62.

[9] Tolchard B. Cognitive-behavior therapy for problem gambling: a critique of current treatments and proposed new unified approach. J Ment Health 2017;26(3):283-90.

[10] Gooding P, Tarrier N. A systematic review and meta-analysis of cognitivebehavioural interventions to reduce problem gambling: hedging our bets? Behav Res Ther 2009;47(7):592-607.

[11] Merkouris SS, Thomas SA, Browning CJ, Dowling NA. Predictors of outcomes of psychological treatments for disordered gambling: a systematic review. Clin Psychol Rev 2016;48:7-31.

[12] Jiménez-Murcia S, Álvarez-Moya EM, Granero R, Jaurrieta N, et al. Cognitivebehavioral group treatment for pathological gambling: analysis of effectiveness and predictors of therapy outcome. Psychother Res 2007;17 (5):544-52.

[13] Jiménez-Murcia S, Granero R, Fernández-Aranda F, Arcelus J, Aymamí MN, Gómez-Peña M, et al. Predictors of outcome among pathological gamblers receiving cognitive behavioral group therapy. Eur Addict Res 2015;21(4):16978.

[14] Müller KW, Wölfling K, Dickenhorst U, Beutel ME, Medenwaldt J, Koch A Recovery, relapse, or else? Treatment outcomes in gambling disorder from a multicenter follow-up study. Eur Psychiatry 2017;43:28-34.

[15] Mestre-Bach G, Steward T, Granero R, Fernández-Aranda F, Mallorquí-Bagué N, et al. The predictive capacity of DSM-5 symptom severity and impulsivity on response to cognitive-behavioral therapy for gambling disorder: a 2-year longitudinal study. Eur Psychiatry 2018 In press.

[16] Cowlishaw S, Merkouris S, Dowling N, Anderson C, Jackson A, Thomas S. Psychological therapies for pathological and problem gambling. Cochrane Database Syst Rev 2012;11:CD008937.

[17] Pickering D, Keen B, Entwistle G, Blaszczynski A. Measuring treatment outcomes in gambling disorders: a systematic review. Addiction 2018;113:411-26.

[18] Aragay N, Jiménez-Murcia S, Granero R, Fernández-Aranda F, Ramos-Grille I, Cardona S, et al. Pathological gambling: understanding relapses and dropouts. Compr Psychiatry 2015;57:58-64

[19] Ledgerwood DM, Petry NM. What do we know about relapse in pathological gambling? Clin Psychol Rev 2006;26(2):216-28.

[20] Challet-Bouju G, Bruneau M, Victorri-Vigneau C, Grall-Bronnec M. Cognitive remediation interventions for gambling disorder: a systematic review. Front Psychol 2017;8:.

[21] Laursen BP, Hoff E. Person-centered and variable-centered approaches to longitudinal data. Merrill Palmer Q 2007;52(3):377-89.

[22] von Eye A, Bogat GA. Person-oriented and variable-oriented research: concepts, results, and development. Merrill Palmer Q 2007;52(3):390-420.

[23] Carbonneau R, Vitaro F, Brendgen M, Tremblay RE. Trajectories of gambling problems from mid-adolescence to age 30 in a general population cohort. Psychol Addict Behav 2015;29(4):1012-21.

[24] Liu W, Lee GP, Goldweber A, Petras H, Storr CL, Ialongo NS, et al. Impulsivity trajectories and gambling in adolescence among urban male youth. Addiction 2013;108(4):780-8.

[25] Slutske WS, Jackson KM, Sher KJ. The natural history of problem gambling from age 18 to 29. J Abnorm Psychol 2003:112(2):263-74.

[26] Nelson SE, LaPlante DA, LaBrie RA, Shaffer HJ. The proxy effect: gender and gambling problem trajectories of iowa gambling treatment program participants. J Gambl Stud 2006;22(2):221-40.

[27] Edgerton JD, Melnyk TS, Roberts LW. Problem gambling and the youth-toadulthood transition: assessing problem gambling severity trajectories in a sample of young adults. J Gambl Stud 2014;31(4):1463-85.
[28] Godinho A, Kushnir V, Hodgins DC, Hendershot CS, Cunningham JA. Betting on life: associations between significant life events and gambling trajectories among gamblers with the intent to quit. J Gambl Stud 2018;34(4):1391-406.

[29] Grune B, Sleczka P, Kraus L, Braun B. OP-34: trajectories of gambling behaviour and gambling problems in outpatient care-results from an ongoing study. J Behav Addict 2017;6(S1):17.

[30] Mann K, Roos CR, Witkiewitz K. Response to Letter to Editor (Precision medicine in alcohol dependence: evidence of efficacy and initial support for comparative effectiveness). Neuropsychopharmacology 2018;43(9):1801-2.

[31] Kranzler HR, McKay JR. Personalized treatment of alcohol dependence. Curr Psychiatry Rep 2012;14:486-93.

[32] Evers K. Personalized medicine in psychiatry: ethical challenges and opportunities. Dialogues Clin Neurosci 2009;11:427-34.

[33] Jara-Rizzo MF, Navas JF, Steward T, Lopez-Gomez M, Jimenez-Murcia S, Fernandez-Aranda F, et al. Impulsivity and problem awareness predict therapy compliance and dropout from treatment for gambling disorder. Adicciones 2018;0(0):1041.

[34] Hodgins DC, el-Guebaly N. The influence of substance dependence and mood disorders on outcome from pathological gambling: five-year follow-up. J Gambl Stud 2010;26(1):117-27.

[35] Jiménez-Murcia S, Tremblay J, Stinchfield R, Granero R, Fernández-Aranda F, Mestre-Bach G, et al. The involvement of a concerned significant other in gambling disorder treatment outcome. J Gambl Stud 2017;33(3):937-53.

[36] Ingle PJ, Marotta J, McMillan G, Wisdom JP. Significant others and gambling treatment outcomes. J Gambl Stud 2008:24(3):381-92.

[37] Oei TPS, Gordon LM. Psychosocial factors related to gambling abstinence and relapse in members of gamblers anonymous. J Gambl Stud 2008;24(1):91105.

[38] Jiménez-Murcia S, Del Pino-Gutiérrez A, Fernández-Aranda F, Granero R, Hakänsson A, Tárrega S, et al. Treatment outcome in male Gambling Disorder patients associated with alcohol use. Front Psychol 2016;7:.

[39] Del Prete F, Steward T, Navas JF, Fernández-Aranda F, Jiménez-Murcia S, Oei TPS, et al. The role of affect-driven impulsivity in gambling cognitions: a convenience-sample study with a Spanish version of the Gambling-Related Cognitions Scale. J Behav Addict 2017;6(1):51-63.

[40] American Psychiatric Association. Diagnostic and statistical manual of mental disorders: DSM-IV-TR. Washington DC: American Psychiatric Association; 2000.

[41] Stinchfield R. Reliability, validity, and classification accuracy of a measure of DSM-IV diagnostic criteria for pathological gambling. Am J Psychiatry 2003;160(1):180-2.

[42] Jiménez-Murcia S, Stinchfield R, Alvarez-Moya E, Jaurrieta N, Bueno B, Granero $\mathrm{R}$, et al. Reliability, validity, and classification accuracy of a Spanish translation of a measure of DSM-IV diagnostic criteria for pathological gambling. J Gambl Stud 2009;25(1):93-104.

[43] Echeburúa E, Báez C, Fernández J, Páez D. Cuestionario de juego patológico de South Oaks (SOGS): Validación española. [South Oaks Gambling Screen (SOGS): Spanish validation]. Anális Modif Cond 1994;20:769-91.

[44] Derogatis LR. SCL-90-R. Cuestionario de 90 síntomas-Manual. Madrid: TEA Editorial; 2002.

[45] Gutiérrez-Zotes JA, Bayón C, Montserrat C, Valero J, Labad A, et al. Temperament and Character Inventory-Revised (TCI-R). Standardization and normative data in a general population sample. Actas Esp Psiquiatr 2004;32 (1):8-15.

[46] Jiménez-Murcia S, Aymamí-Sanromà M, Gómez-Peña M, Álvarez-Moya E, Vallejo J. Protocols de tractament cognitivoconductual pel joc patològic $\mathrm{i}$ d'altres addiccions no tòxiques. [Cognitive-behavioral treatment protocols for pathological gambling and other nonsubstance addictions] Barcelona. 2006.

[47] Jiménez-Murcia S, Aymamí-Sanromà M, Gómez-Peña M, Álvarez-Moya E, Vallejo J. Protocols de tractament cognitivoconductual pel joc patològic i d'altres addiccions no tòxiques. Barcelona, Spain: Hospital U; 2006.

[48] Jiménez-Murcia S, Álvarez-Moya EM, Granero R, Neus Aymami M, GómezPeña M, Jaurrieta N, et al. Cognitive-behavioral group treatment for pathological gambling: analysis of effectiveness and predictors of therapy outcome. Psychother Res 2007;17(784375804):544-52.

[49] Jiménez-Murcia S, Granero R, Fernández-Aranda F, Arcelus J, Aymamí MN, Gómez-Peña M, et al. Predictors of outcome among pathological gamblers receiving cognitive behavioral group therapy. Eur Addict Res 2015;21(4):16978.

[50] Enders C, Bandalos D. The relative performance of full information maximum likelihood estimation for missing data in structural equation models. Struct Equ Model A Multidiscip J 2001;8(July (3)):430-57.

[51] Graham JW. Missing data analysis: making it work in the real world. Annu Rev Psychol 2009;60(January (1)):549-76.

[52] Lo Y, Mendell N, Rubin D. Testing the number of components in a normal mixture. Biometrika 2001;88:767-78.

[53] Kreuter F, Muthén B. Analyzing criminal trajectory profiles: bridging multilevel and group-based approaches using growth mixture modeling. J Quant Criminol 2008;24(1):1-31.

[54] Jung T, Wickrama KAS. An introduction to latent class growth analysis and growth mixture modeling. Soc Personal Psychol Compass 2008;2(1):302-17.

[55] Nylund KL, Asparouhov T, Muthén M, Muthén BO. Deciding on the number of classes in latent class analysis and growth mixture modeling: a monte carlo simulation study. Struct Equ Model 2007;14(4):535-69.

[56] Kelley K, Preacher KJ. On effect size. Psychol Methods 2012;17(2):137-52. 
[57] Simes RJ. An improved Bonferroni procedure for multiple tests of significance. Biometrika 1986;73:.

[58] Jimenez-Murcia S, Aymamí N, Gómez-Peña M, Santamaría JJ, Álvarez-Moya E, Fernández-Aranda F, et al. Does exposure and response prevention improve the results of group cognitive-behavioural therapy for male slot machine pathological gamblers? Br J Clin Psychol 2012;51(1):54-71.

[59] Gómez-Peña M, Penelo E, Granero R, Fernández-Aranda F, Alvarez-Moya E, Santamaría JJ, et al. Correlates of motivation to change in pathological gamblers completing cognitive-behavioral group therapy. J Clin Psychol 2012;68(7):732-44.

[60] Ladouceur R, Lachance S, Fournier P-M. Is control a viable goal in the treatment of pathological gambling? Behav Res Ther 2009;47(3):189-97.

[61] Stea JN, Hodgins DC, Fung T. Abstinence versus moderation goals in brief motivational treatment for pathological gambling. J Gambl Stud 2015;31 (3):1029-45.

[62] Hodgins DC, El-Guebaly N. Retrospective and prospective reports of precipitants to relapse in pathological gambling. J Consult Clin Psychol 2004;72(1):72-80.

[63] Blaszczynski A, McConaghy N, Frankova A. Control versus abstinence in the treatment of pathological gambling: a two to nine year follow-up. Br J Addict 1991;86(3):299-306.

[64] Dowling N, Smith D. Treatment goal selection for female pathological gambling: a comparison of abstinence and controlled gambling. J Gambl Stud 2007;23(3):335-45.

[65] Dowling N, Smith D, Thomas T. A preliminary investigation of abstinence and controlled gambling as self-selected goals of treatment for female pathological gambling. J Gambl Stud 2009;25(2):201-14.

[66] Ladouceur R. Controlled gambling for pathological gamblers. J Gambl Stud 2005;21(1):49-57.

[67] Slutske WS, Piasecki TM, Blaszczynski A, Martin NG. Pathological gambling recovery in the absence of abstinence. Addiction 2010;105(12):2169-75.

[68] Menchon JM, Mestre-Bach G, Steward T, Fernandez-Aranda F, Jimenez-Murcia S. An overview of gambling disorder: from treatment approaches to risk factors. F1000Research 2018;7:434, doi:http://dx.doi.org/10.12688/ f1000research.12784.1 eCollection 2018.

[69] Yakovenko I, Quigley L, Hemmelgarn BR, Hodgins DC, Ronksley P. The efficacy of motivational interviewing for disordered gambling: systematic review and meta-analysis. Addict Behav 2015;43:72-82.
[70] Hopwood CJ, Schade N, Matusiewicz A, Daughters SB, Lejuez CW. Emotion regulation promotes persistence in a residential substance abuse treatment. Subst Use Misuse 2015;50(2):251-6.

[71] Heilman RM, Crissan LG, Houser D, Miclea M, Miu AC. Emotion regulation and decision making under risk and uncertainty. Emotion 2010;10(2):257-65.

[72] Goudriaan AE, Oosterlaan J, De Beurs E, Van Den Brink W. Decision making in pathological gambling: a comparison between pathological gamblers, alcohol dependents, persons with Tourette syndrome, and normal controls. Cogn Brain Res 2005;23(1):137-51.

[73] Claes L, Jiménez-Murcia S, Santamaría JJ, Moussa MB, Sánchez I, Forcano L, et al. The facial and subjective emotional reaction in response to a video game designed to train emotional regulation (Playmancer). Eur Eat Disord Rev 2012;20(6):484-9.

[74] Fagundo AB, Santamaría JJ, Forcano L, Giner-Bartolomé C, Jiménez-Murcia S, Sánchez I, et al. Video game therapy for emotional regulation and impulsivity control in a series of treated cases with bulimia nervosa. Eur Eat Disord Rev 2013;21(6):493-9.

[75] Fernández-Aranda F, Jiménez-Murcia S, Santamaría JJ, Gunnard K, Soto A Kalapanidas E, et al. Video games as a complementary therapy tool in mental disorders: PlayMancer, a European multicentre study. J Ment Health 2012;21 (4):364-74.

[76] Tárrega S, Castro-Carreras L, Fernández-Aranda F, Granero R, Giner-Bartolomé C, Aymamí N, et al. A serious videogame as an additional therapy tool for training emotional regulation and impulsivity control in severe gambling disorder. Front Psychol 2015;6:1721.

[77] Jiménez-Murcia S, Fernández-Aranda F, Kalapanidas E, Konstantas D, Ganchev $\mathrm{T}$, Kocsis O, et al. Playmancer project: a serious videogame as an additional therapy tool for eating and impulse control disorders. Annu Rev Cyber Ther Telemed 2009;7:163-6.

[78] Gay A, Boutet C, Sigaud T, Kamgoue A, Sevos J, Brunelin J, et al. A single session of repetitive transcranial magnetic stimulation of the prefrontal cortex reduces cue-induced craving in patients with gambling disorder. Eur Psychiatry 2017;41:68-74.

[79] Makani R, Pradhan B, Shah U, Parikh T. Role of Repetitive Transcranial Magnetic Stimulation (rTMS) in treatment of addiction and related disorders: a systematic review. Curr Drug Abuse Rev 2018;10(1):31-43. 